\title{
La double vie de Veronique DVD
}

\author{
By Jan Uhde
}

Spring 2006 Issue of KINEMA

A real surprise for all film aficionados is this set of Kieślowski's chef-d'œuvre issued by the respected MK2 (Marin Karmitz), featuring an HD restoration with three hours of supplements, including interview with Irène Jacob, Ruben Korenfeld's 53-minute unpublished documentary Kieślowski - Dialogue (1991), and three Kieślowski shorts: Fabryka (Factory, 1970); Szpital (Hospital), 1976; and Dworzec (Railway Station, 1980). [The UK DVD issue of Veronique (Artificial Eye) was made available within months. Criterion isued a Region 1 edition late in 2006.]

Double Life of Veronique, one of Kieślowski's most haunting films, is a kind of bridge between the director's "Polish" and "French" perspectives; it also spearheaded the director's international recognition.

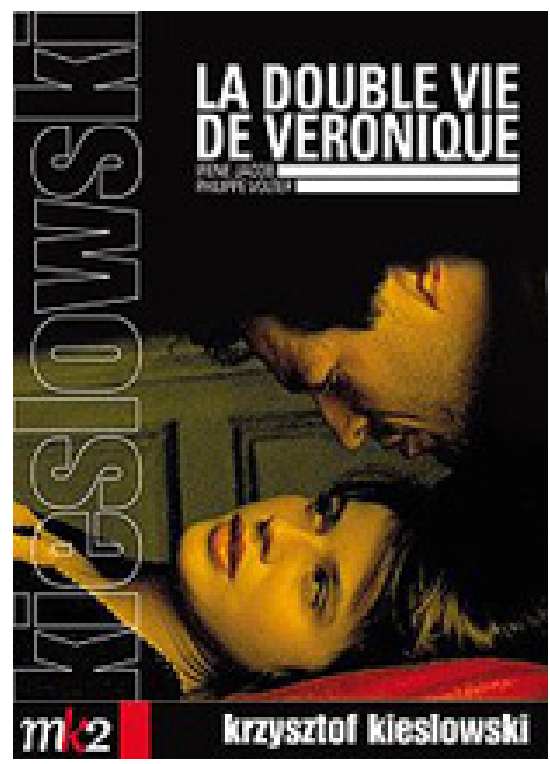

Figure 1: LA DOUBLE VIE DE VERONIQUE DVD (Krzysztof Kieślowski, 1991). PAL, R-2, 2x DVD-9, MK2. 2-disc set Edition Collector. English subtitles. Includes a numbered, matted 6-frame 35mm film strip from a theatrical release print. EUR 24.99 .

Unfortunately, there are many DVDs far below the professional quality and editorial care of those mentioned above. A number of DVD publishers produce discs ranging from below-average to simply atrocious - and they may not even be cheap. This is particularly annoying when the subject of such abuse are films of exceptional artistic quality. They may be transferred from substandard videotapes, their original widescreen ratio may be reduced to a "flat" format, they may suffer from washed-out subtitles, reduced length or arbitrary attempts to censor them.

For example, the US DVD edition of Miloš Forman's 1981 film Ragtime, is missing scenes with the protofeminist Emma Goldman included in the theatrical release; they may be construed as having implicit lesbian undertones. Elsewhere, the bare breasts of Evelyn Nesbit (Elisabeth Mc Govern) are digitally masked. Apparently, the American DVD was bowdlerised to obtain a more lucrative PG rating. In total, the 155minute film shrank on the US-made DVD to 115 minutes! The UK edition of the same title is only seven minutes shorter than the movie's theatrical length - but this is a "flat" 4:3 pan-and-scan format, with a loss of over $40 \%$ viewing area (the US edition more or less retains the original format of 2.35:1). 
Several Pasolini DVDs, including Accattone (Water Bearer Films) are of exceptionally poor quality: the subtitles are often illegible. Hou Hsiao Hsien's The Puppetmaster DVD (Fox Lorber) is poor; its widescreen ratio was converted to flat format.

It is not easy to find on the Web reliable data on the quality of a DVD transfer, or on the existence of a better alternative. Most disc sellers do not publish such information, for obvious reasons. Critical reviews on the Internet may be sometimes useful. One of the best sources of comprehensive and reliable technical quality DVD reviews on the web is the admirable DVD Beaver website (http://www.dvdbeaver.com), managed by the tireless Canadian Gary Tooze.

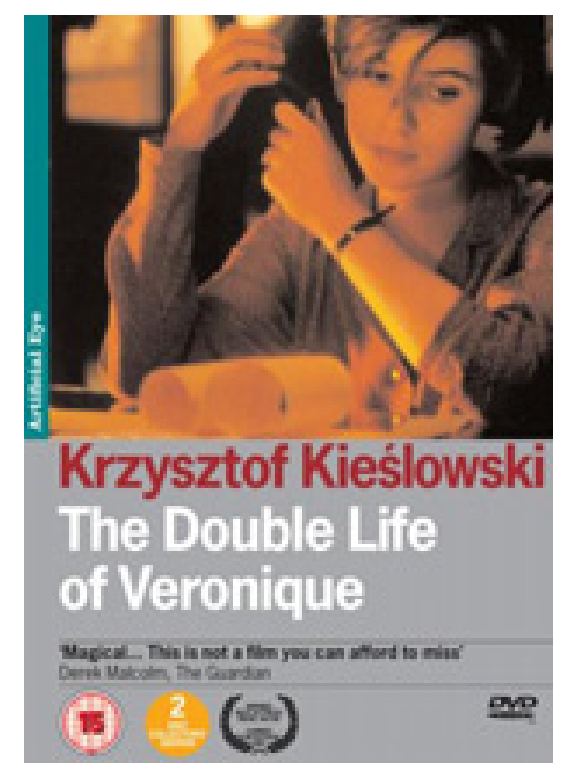

Figure 2: THE DOUBLE LIFE OF VERONIQUE DVD, the UK edition

\section{Author Information}

Jan UHDE is Professor Emer. (Film Studies) at the University of Waterloo, Ontario, Canada. Born in Brno, Czech Republic. Graduated (MA) from the Faculty of Arts, Masaryk University, Brno; PhD received at the University of Waterloo, Ontario, Canada. He taught at the University of Waterloo (1970-2012) where he founded a General and Honours BA program in Film Studies at the Department of Fine Arts.

Publications: Latent Images: Film in Singapore Second edition, with Yvonne Ng Uhde (Ridge Books, National University Press of Singapore, 2010); Latent Images: Film in Singapore, with Yvonne Ng Uhde (Oxford University Press, 2000); Latent Images: Film in Singapore CD-ROM (2003, co-author); Vision and Persistence: Twenty Years of the Ontario Film Institute (University of Waterloo Press, 1990) and Ontario Film Institute Programming Activities Index 1969-1989 (Toronto: Ontario Science Centre, 1990). He co-edited the Place in Space: Human Culture in Landscape (Proceedings from the Second International Conference of the Working Group "Culture and Landscape" of the International Association of Landscape Ecology, Pudoc Scientific Publishers, Wageningen, Holland, 1993). Jan Uhde has published articles and reviews in several countries (including Canada, USA, Germany, Italy), participated in international juries at film festivals and presented papers at international conferences in North America and Europe. In 1998/99, he was a visiting researcher at the School for Film and Media Studies, Ngee Ann Polytechnic, Singapore.

His professional and research interests focus on Singapore cinema; the identification and distancing mechanisms of the film viewer; the non-authored modifications and manipulation of films; and specific aspects of film history, including the Central European cinema.

He founded KINEMA in 1993. 